
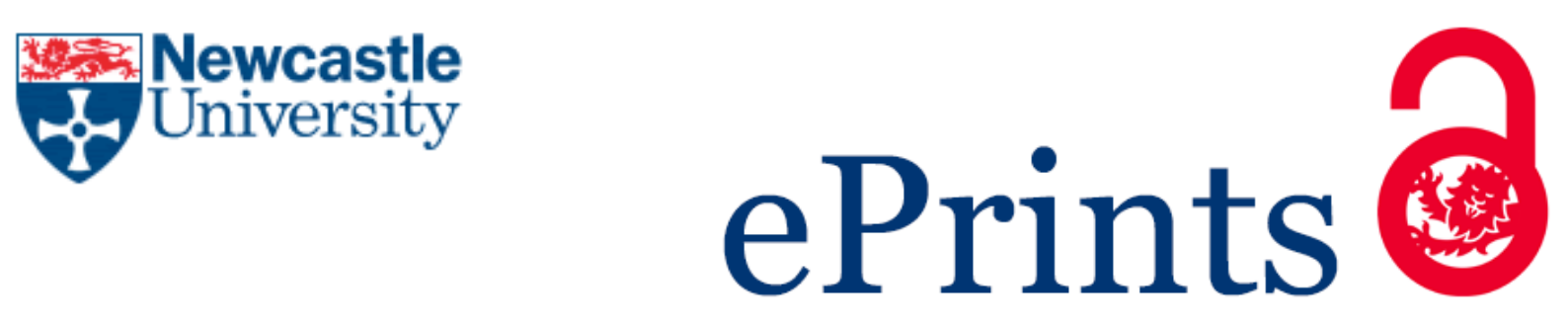

\author{
Gray A, Wilson R, Jenkings KN, Harrison D, Martin $M$. \\ Information Sharing in Services for Military Personnel in Transition \\ to Civilian Life.
}

Public Money and Management 2017, 37(1), 15-22.

\title{
Copyright:
}

This is an Accepted Manuscript of an article published by Taylor \& Francis in Public Money and Management on 24/11/2016, available online: http://dx.doi.org/10.1080/09540962.2016.1249226

Date deposited:

$23 / 09 / 2016$

Embargo release date:

24 May 2018

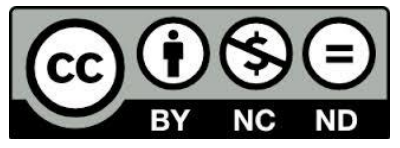

This work is licensed under a

Creative Commons Attribution-NonCommercial-NoDerivatives 4.0 International licence 


\section{Information-sharing in services for military personnel in transition to civilian life}

\author{
Andrew Gray, Rob Wilson, K. Neil Jenkings, Deborah Harrison and \\ Mike Martin
}

An analysis of policy and practice documents on information-sharing in the transition of military personnel into civilian life finds (1) a commitment to enhancing information-sharing to support integrated service provision and meeting information needs for those in transition; (2) a complex transition pathway along which the responsibility for co-ordination of transition shifts from service providers to those in transition; (3) a lack of attention to operationalizing information-sharing for different service circumstances and managing barriers and drivers of different modes of information-sharing; (4) the potential for developing a framework for managing information-sharing; and (5) a need for further research to draw on the evidence of transitions and information-sharing in other policy sectors.
Life's transitions provide opportunities for personal development. They also expose our vulnerabilities, especially when we have become dependent on an institution that has provided for us. The casualties of these transitions have been much studied by psychologists and social workers (Burgess-Allen et al., 2005; Wade and Dixon, 2006; Stein, 2012). However, there has been less attention in western societies on the systematic management of personal transitions than on organizational transitions (Bridges, 2004).

However, after the most intense period of combat operations since the Second World War, increasing political and organizational attention is being paid to the needs of those who have served as members of the UK's armed forces and are returning to civilian life. If there has been a particular focus in the mass media on those suffering from the effects of front-line combat, including post traumatic stress disorder, there is also increasing recognition of the generic needs created by the process of transition itself, especially where accompanied by health, housing and associated social care needs.

Supporting those being discharged from the armed forces is not new. Indeed, there are organizations with a long and distinguished history of provision. Nationally, these include the British Legion (founded in 1921), the Veterans Welfare Service (VWS) (founded in 1948), and the Veterans Advisory and Pensions
Committee and its predecessors. Specific national services for employability within the Careers Transition Partnerships are also well established and provide a focused bridge between serving and civilian life. More recent entrants include Help for Heroes, Forward Assist and the Naval Families Federation. Locally, there is a host of organizations often offering niche volunteer support with limited resources and geographical reach but backed up by national networks such as the Confederation of Service Charities (Cobseo) and regional hubs such as Finchale College in County Durham. The Armed Forces Community Covenant (MOD [Ministry of Defence], 2011) has also stimulated central and local government and the National Health Service (NHS) to be more active in identifying personnel in transition and meeting their needs.

In some ways, personnel leaving the armed forces are akin to those leaving any institutional setting. However, some see the military as a classic 'total institution' (Goffman, 1968) and its leavers as a homogenous group. This is in part due a perception of military training and wider socialization as producing a uniform person. Yet, the uniform, as well as media stereotyping, hide the varied experiences of the air force, army and navy and their constituent services (Jenkings et al., 2008; Woodward et al., 2009). Indeed, one of the features of the care and welfare of exservice personnel and their families is the sheer diversity of the participants, their needs and
Andrew Gray is a Visiting Fellow in the Centre for

Knowledge

Innovation Technology and Enterprise (KITE),

Newcastle

University, $U K$.

Rob Wilson is

Professor of

Information Systems

Management and

Director of KITE.

K. Neil Jenkings is Senior Research

Associate, Newcastle University.

Deborah Harrison is a Research Associate at Durham

University and a Visiting Fellow at KITE.

Mike Martin is a Senior Research Advisor at KITE. 
personal experience. The army, for example, has a system of regiments which have their own specialisms, training, traditions and post-service support. Moreover, personnel join the services at different ages and serve for different periodsthose joining straight from school may have little knowledge and experience of civil society to draw upon when they return to it, especially if they have served for many years. Those that have been single will have lived in barracks with all services provided for them. Others may have married and lived in military accommodation with little integration into local civil society. When the varied experiences of combat and its physical and mental trauma are added to the mix, we may discern a diverse population of individuals and families within the armed forces.

While in service, these personnel are provided for from a single source-the military itself. They are informed of and delivered resources to which they have entitlement and allocation criteria are generally easily ascertained. Once they leave the armed forces, however, 'Life outside is a very different prospect, fraught with uncertainty, irregularity and, in many ways, a very different value system' (Nordass, 2009). Here information and resources are distributed by a large number of, often unfamiliar, providers with varying eligibility criteria. For most personnel, understanding and making the transition is not too problematic and they may require few, if any, of the services provided. For others, and often those with the most needs, it is a bewildering prospect; their needs are at risk of not being identified and provided for by civil society, thus undermining their ability to function.

Some needs are peculiar to or more prevalent in the military. In housing, for example, exservice personnel may not be eligible for council or social housing because they can be regarded as having made themselves intentionally homeless by leaving the employment of the armed forces. Financial problems may follow the loss of regular employment income and include mounting debts as they search for work. The drinking culture of the armed forces, formerly managed by the military as if hidden in plain view, may in civilian life emerge problematically and require counselling or other service provision. Similarly, mental health problems that may have been contained within the military's collectivist institution can be exacerbated by the transition to an individual-orientated civil society. The family, too, may be affected as it emerges from the total institution under transition pressures that may threaten family relationships.

In such situations the accessing of information and services by ex-military personnel (and their families) can become highly problematic. They may suffer from a lack of personal self-esteem as they move from positions of authority over personneland equipment to ones of dependency on family members and civilian 'others', and from an environment where they can navigate the social system with ease to one where it is unfamiliar, incoherent and confusing.

In recent years governments and others working for the military have not only recognized these scenarios, butalso sought to develop services for reducing their incidence and severity. At the same time, the provision of similar integrated services in the public realm at large has recognized the need not only for information-sharing within them but also its effective governance. Those working with ex-military personnel, and their families, are now under increasing scrutiny from public sector commissioners to demonstrate that as organizations and practitioners they have the requisite management policies and systems in place for the appropriate use of information.

\section{Scope and method of investigation}

Recognizing and seeking to meet these needs and the attendant requirements for informationsharing in services for military personnel in transition to civilian life, the Forces in Mind Trust, with the Association of North East Councils (ANEC), commissioned an exploratory study of the information-sharing practices among those providing services for those personnel in transition in north east England. Specifically included was a commission to:

- Scope out the needs and information-sharing requirements for the veterans, their carers and families and the organizations working with them.

- Examine the barriers/drivers for informationsharing and structures and processes to highlight and assess the levels and types of approaches within the key contexts and case studies and identify priorities, gaps and opportunities.

The primary empirical data gathering comprised a survey of practitioners and their services, interviews with selected providers and discussions with focus groups. To inform this empirical investigation (whose findings will be presented elsewhere), the research included an analysis of documents and reports on the policy and practice of the transition of military personnel into civilian life.

Working within the commissioned aims and resources, the study identified 40 documents of three overlapping types: documents setting out 
policy, implementation or practice guidelines; reports reviewing and scrutinizing policy and practice; and prescriptions for reform of policy and practice.

These documents were examined for contributions to the principal research objects. While most make reference to the high priority now awarded to the care of ex-military personnel, some (for example Talbot Rice, 2009) note that until the increase in combat deployments since 2000 and a very visible campaign for Ghurkha residency rights in the $\mathrm{UK}$, this priority fluctuated. However, the Armed Forces Covenant of 2011 has focused the attention of the policy and practice community on meeting the needs of these personnel including during their transition into civilian life.

The documents, however, do not always agree on core terms such as 'veteran' and 'transition'. 'Veteran', for example, is avoided by the Forces in Mind Trust partly because not all those who have left the service regard themselves as such (it traditionally being reserved for those with active war service). Thus we here use the admittedly lessconcise term 'ex-service personnel' to refer to 'anyone who has served for at least a day in HM Armed Forces, whether as a Regular or a Reservist' (Forces in Mind Trust, 2013, p. 11).

Such a definition, however, requires recognizing at least three groups with distinct transitional needs:

- Regular service leavers are those completing a planned contract of duty and for whom transitional services are provided.

- Early service leavers are those "who are discharged (a) compulsorily...(or)...(b) at their own request from the trained strength or untrained strength, having completed less than 4 years' service' (MOD quoted in Forces in Mind Trust, 2013 , p. 16). Early service leavers are not entitled to the level of support offered to regular service leavers.

- Reservists enter short-term active service and return to civic society in a recurring pattern, usually without transitional support unless wounded on duty; the policy to increase their numbers and deployments has implications for transitional support services.

We also adopted, for purposes of analysis, the Forces in Mind Trust definition of transition as 'the period of re-integration into civilian life from the Armed Forces...it is taken to start with the point in service at which Service personnel start their resettlement process and then continues...for three years from discharge'. The reference to 'resettlement' describes the 'formal processes and procedures by which transition is managed, and the formal support provided to service leavers during transition. It starts with the activation of the Resettlement process and continues until the end of Resettlement provision': a period of usually two years (Forces in Mind Trust, 2013, p. 16). For the trust, 'A good transition is one that enables ex-Service personnel to be sufficiently resilient to adapt successfully to civilian life, both now and in the future. This resilience includes financial, psychological, and emotional resilience, and encompasses the ex-Service person and their immediate families' (Forces in Mind Trust, 2013, p. 13).

\section{Information needs and information-sharing}

Information-sharing is often seen as the lifeblood of publicservices. However, effective informationsharing across organizational, professional and policy domains is hard to achieve. Government information-sharing policy has often been focused on hierarchical regulations and initiatives aimed at compliance, whereas the reality of practice consistently reveals complex interorganizational socio-technical issues (see, for instance, 6 et al., 2005; Richardson and Ashtana, 2006; Dawesetal., 2009; Wilson et al., 2011; Yang and Maxwell, 2011; Cornford et al., 2013). This documentary review explores the extent to which these characteristics also apply to the transition of military personnel into civilian life. For the MOD:

Support should be provided to all Service personnel to assist in their transition from Service to civilian life. Provision should include training, education, appropriate healthcare referral and job-seeking preparation and assistance. It should also include informationand guidance on housing and financial management and the support that is available from both Government departments and the voluntary sector. The level of support will be dependent upon individual circumstances (MOD, 2011, p. 8).

Such individual circumstances are central to the meeting of needs. Some documents (for example House of Commons Committee of Public Accounts, 2008) express an accepted view that a large majority of transitions are made satisfactorily. Most personnel are largely selfsufficient and need only modest support. Others, however, can be very dependent, with transition adding to their vulnerabilities and needs for special care, support, or protection because of disability, or risk of abuse, or neglect. For example, only $9 \%$ of military recruits in 2008 had passed 
GCSE English at grades A*-C compared with $61 \%$ nationally (Lewis et al., 2013 ); $14 \%$ of service leavers (more from the early leavers) could be classified as 'vulnerable' (Thomas et al., 2013); $44 \%$ of vulnerable leavers had a psychiatric diagnosis (Iversen, 2005); and the particular vulnerabilities of ex-military personnel increase their risks of entering the criminal justice system (Macdonald, 2014). Such military personnel thus present the greatest needs, including for making effective use of information, for the transitional services.

The predominant focus of the reviewed documents is on the needs themselves, rather than information-sharing. These relate principally to functional support and 'clear, accurate and timely' information (Ashcroft, 2014, p. 173) about employment, housing, training and education, health and social care, and supporting skills such as financial management. The wide-ranging Ashcroft Report includes specific recommendations for:

- A personal development plan.

-A veteran's card with an assistance telephone number and website address.

- A single contact centre for service leavers and veterans, created through a partnership between the VWS and major charities.

- An improved VWS website, with areas for those needing support and for professionals and practitioners.

- A digital 'app' for veterans to access a comprehensive portal for information.

Ashcroft also noted (2014, p. 176) the need for ex-service personnel to make sure that they provide relevant agencies with their resettlement address. In the north east of England, the Joint Health Overview and Scrutiny Committee argued that this would 'enable local authorities, and other organizations, to better plan to address need and co-ordinate relevant support for the ex-service community in each part of the region' (JHOSCNELA [Joint Health Overview and Scrutiny Committee of North East Local Authorities], 2013, pp. 3-4).

The documents also provide insights into the transition pathway and the way needs are raised and met along it. Herman and Yarwood (2014) report that even those who make effective transitions experience feelings of loss and separation. This suggests conceptualizing transition as a process, rather than an event, in order to understand how individuals negotiate their identities in changing circumstances. Such a longitudinal perspective recognizes the many stages of the transition pathway starting with original recruitment, continuing through various points of service including the decision to leave the service, and then the return to and resettlement into civilian life (Forces in Mind Trust, 2013, p. 14 and subsequent chapters). Each stage brings its unique information needs to add to those common to the pathway as a whole.

From the documents we also identify the very large number and wide range of agents involved in the transition pathway. These fall into three sets with different roles and needs:

- Those in transition and their families.

- Military, public, private and third sector service providers.

- Friends, supporters and advocates of those in transition.

Although the documents are not specific, we can see that these agents are involved in different combinations at the different stages of transition. While those in transition are still in service, the military hosts are not only the core providers but act as the co-ordinators of the whole process of meeting personnel needs. After leaving the service, however, those in transition may join one or more possible career pathways (employment, apprenticeship, further education, higher education and business start-up) and face a more complex pattern of multiple service providers. At this and subsequent stages, the responsibility for co-ordination shifts increasingly to the ex-military personnel themselves, who often find the complexity of these service combinations difficult to navigate (Forces in Mind Trust, 2013, p. 80). It is possible to imply from the documents that it is at these stages that the friends, supporters and advocates are most significant and effective (Weissman et al., 2005).

Documents frequently claim the desirability for service providers to join-up more effectively along this transition pathway. Indeed, 'Join the dots between support pathways' is Guiding Principle 9 of the Forces in Mind Trust (2013, p. 80). The majority of documents call for better communication and sharing of information and more joined-up work. Recommendations include formal information-sharing protocols between the armed forces and local authorities to 'enable local authorities to properly assess and plan to meet the needs of the ex-service community as a specific group' (JHOSCNELA, 2011, p. 5) and more collaborative arrangements such as forums and networks to meet more effectively the needs of both those in transition and those providing services (Gateshead Council, 2014, p. 1).

While the documents provide these and 
related insights into the states and agents of the transition pathway, they do not set out its operational implications. They have little to say about how these more collaborative arrangements might be established and governed, especially in an increasingly mixed economy of service provision for clients. Moreover, they do not systematically explain what information-sharing entails and requires to be effective for whom in what circumstances.

This literature does in passing, however, refer to different information-sharing practices and the interdependent relationships they manifest. We noted here some resonance with the organizational literature on interdependency and found Thompson's typology of sequential, pooled and reciprocal interdependency descriptively helpful in characterizing these practices (2003).

Using Thompson's constructs, we define sequential information-sharing (see figure 1) as the unilateral passing of information from one stage or agent to another in sequence along the transition pathway. It recognizes that, for transition to be effective, agents need to provide information to those in transition as determined by the stages at which the agents and users relate. This is the most common mode of informationsharing described in the documents (for example MOD, 2014). It arises, for example, in recommendations in the form of 'at stage $\mathrm{X}$ those in transition need information about Y'. It is also implied in discussions about the needs for service providers to pass on information about those in transition to service providers at the next stage (for example medical records from military to NHS primary care).

Pooled information-sharing comprises the depositing of information into shared facilities accessible by other service providers and users. It is the mode characteristic of web-based directories provided by, for example, the Confederation of British Service Charities and by Veterans Scotland. It is also the mode championed by those arguing for collaborative arrangements that extend access through specifically designed portals to information warehouses for those in transition and their supporters (for example Ashcroft, 2014).

Reciprocal information-sharing comprises information exchange in dynamic and mutual relations. In this mode of sharing, the information outputs of one party are the contingent information inputs of another in a continuing chain of engagements. This mode is characteristic of sharing between partners in integrated multiagency service provision, between those in transition with each other, and between service providers and those in transition along the whole of the transitional pathway. This reciprocal sharing is implied by many of the discussions of joint working or integrated provision; it is the most complex and most demanding to establish and sustain.

We recognize that we are presenting patterns that document authors may be unaware of. Yet, we might have expected those elaborating the need for information-sharing to have paid explicit attention to what types of sharing might be appropriate in what circumstances.

\section{Information-sharing barriers and drivers}

The patterns of information-sharing described in the previous section are behaviourally distinct; they exhibit varying interactions and interdependencies along the transition pathway. They also imply differential conditions in which they are functional and hint at the barriers and drivers to meeting the information needs of those in transition.

The documents provide illustrations of these barriers and drivers. Some are essentially

Figure 1. Patters of personal information-sharing.

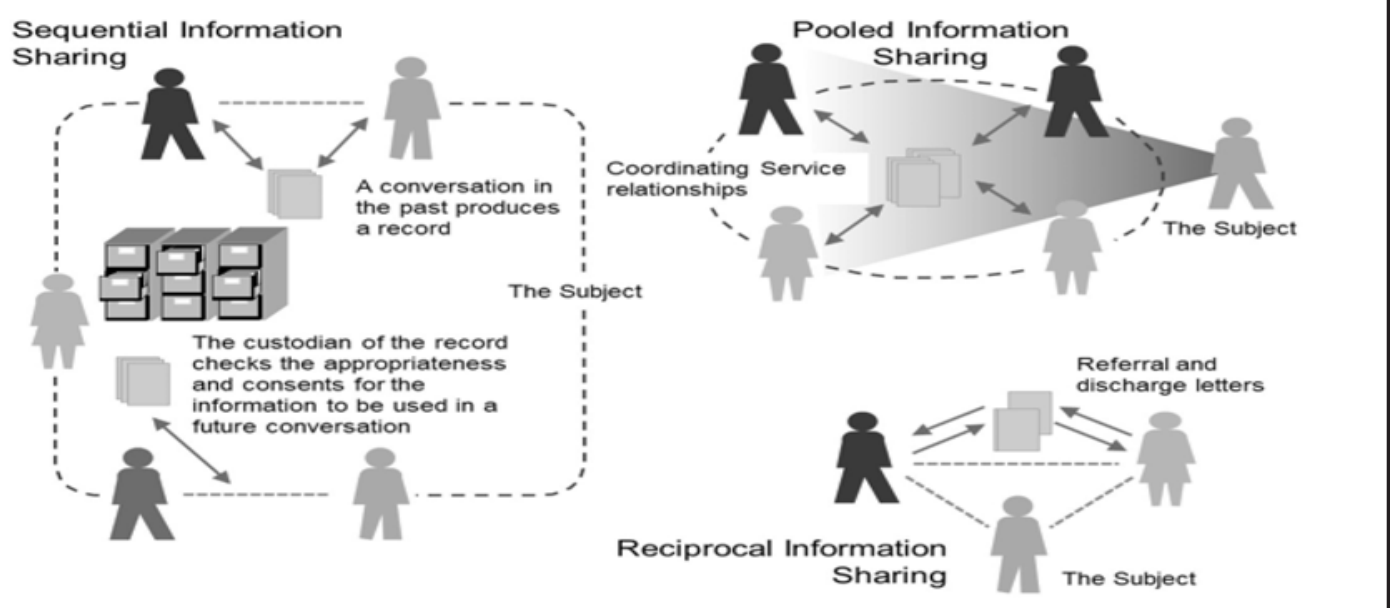


technical. They include the legalities of information-sharing (including consent and data protection), the qualities of validity, reliability and timeliness of data, the fitness of purpose of hardware and software systems and processes by which data are translated into information for decisions, and the functionality of communication facilities. Most reports focus on aspects of personal access to data and the protection of that data in use:

- The legal basis for information-sharing (Department for Children, Schools and Families and Department for Communities and Local Government, 2008: Section 2; Information Commissioner's Office undated, including section C2 on Exemptions from the Data Protection Act; CEIS, 2014).

- Basis of data confidentiality and how to preserve it while sustaining a functional regime of sharing (DH, 2013; CEIS, 2014; Information Commissioner's Office, undated).

- Anonymization of data (DH, 2013; CEIS, 2014).

- Risk assessment in information-sharing (CEIS, 2014).

Some identify additional technical challenges:

- Recording personnel transfers and the connectivity between military and civilian public service computer systems (Lewis et al., 2013, p. 31).

- Training: as in a template provided the Centre of Excellence for Information-Sharing (CEIS, 2014).

Common to all is the fundamental challenge of identifying what the information requirements are, where and how the information is held, and who needs to share it.

For the Forces in Mind Trust, 'Good transition support is about Tailoring, Timing and Take-up' (2013, p. 72). Perhaps these neatly summarise the organizational barriers and drivers of information-sharing. These structural, processual and behavioural elements include the effectiveness as well as comprehensibility of the allocations of function and authority, the processes by and through which decisions are made that affect those in transition, and the dispositions of service providers and those in transition to engage effectively. Among such drivers and barriers specifically cited by the documents are:

- Governance issues, the identification of stakeholders and the development of protocols and processes for information-sharing-see the toolkit developed by the CEIS.

- Co-ordinative challenges such as those recognized in the recommendations of the Joint Health Oversight and Scrutiny Committee of 'brokering' assistance by local authorities, 'better co-ordination of work across the region', 'sharing examples of best practice', 'ensuring that the Transition Protocol is understood and that specific individuals are mandated appropriately to take on these roles', and 'developing' with other organizations a 'formal process' for referring vulnerable service leavers into specific services (JHOSCNELA, 2011, for example R24, R2729); the extensive scale and scope of the organizations involved in effecting these recommendations are reported in JHOSCNELA (2013).

- Behaviours and attitudes (among leavers) that could apply problematically to informationsharing (Forces in Mind Trust, 2013, pp. 3337) and might explain the variable take up of and access to transition support identified by the House of Commons Committee of Public Accounts (2008).

A third group of drivers and barriers are political. They include policy changes in the structure of the armed forces, in particular the plan to increase the proportion of reservists following the Future Reserves 2020 report (Independent Commission, 2011). The extended use of reservists will add to the complexity of transitions in and out of service that need to be factored into strategic thinking.

Political drivers include perhaps the most powerful of all - the current priority accorded to providing for the needs of ex-military personnel and the commitment by those providing services to make a difference to client lives. However, the documents tend to miss the opportunity to build concretely on this priority. They tend to prefer policy statements of meeting information needs and sharing, rather than strategies for practice. They overlook the challenges presented by differentiated interests in effecting common policies and practices, and the way such interests of those providing services may conflict including in an increasingly mixed economy where commercial interests have to be accommodated with service interests.

The issues are partly about how needs are prioritized by the policy community (MOD, 2011) and local commissioners of services (JHOSCNELA, 2011, p. 10; Lewis et al., 2013) to ensure that ex-military personnel are not disadvantaged on return to civilian life by their service in the military. As the care and welfare of 
ex-military personnel, their dependants and carers is increasingly reliant on 'civilian' services, such as the NHS and local government, the sharing of information between the military and civilian agencies involved is emerging as a significant area of UK government investment, including through the MOD Gateway (a national helpline) and Project Cortisone (for interoperatability with health services). But the issues also include the mitigation of risks for leavers in sensitive areas such as Northern Ireland (Ashcroft, 2014, p. 102) and in the context of heightened security alerts.

Implicit throughout is the inherent dilemma between the force to share and the force to protect information. Windsor (2014) addresses some of the issues more generally, including ethical data management, data storage, privacy policy and data-sharing. While sounding both technical and organizational, these issues are in essence political as they require a determination of the values and priorities to be allocated to the respected forces to share and protect information and the political will to put into effect whatever is so determined.

\section{Conclusion}

In his preface to the Forces in Mind Trust Report, Ray Lock, its chief executive speculates on a good transition:

We were tidying out the garage last week and I came across my last service kit bag, stuffed full of mouldy boots, socks and other stash I thought I might need when I left, but never did. I came across a tattered credit card-size piece of cardboard. I thought at first it must have been an old Card Alpha, the rules of engagement we used to carry everywhere; but I read it and realized that it was an idiot's guide to transition with the grand title 'Guiding Principles for a Good Transition'. It's been a while since I first got that; but funny old thing, they worked for me, and for everyone else involved in transition. Rules of engagement for transition-maybe that was the key to a good transition.

The documents reviewed here provide a substantial amount of material about how this good transition might be realized and even what such rules of engagement might look like. They display a strong commitment to enhancing information-sharing to supportintegrated service provision and meeting the information needs of military personneland their families in transition. They reveal the complex pattern of stages and agents in the transition pathway along which the responsibility for co-ordination of transition shifts from service providers to those in transition. They illustrate the problems brought by non joined-up, unaligned or fragmented provision.

However, the documents contribute only indirectly to our understanding of what information-sharing entails, its different requirements in different circumstances and how the barriers and drivers of information-sharing may be managed. Perhaps these gaps reflect the nature of the documents reviewed. Even the most substantial of them, and some are very substantial both in commitment and scope, emphasise their principal potential to influence policy and practice development. Thus they tend to pay more attention to the general thrust of their recommendations, rather than the practical implications of making them work.

That leaves considerable opportunities for further work in both service development and research. First, we can forge an informationsharing framework that incorporates the management of sequential, pooled and reciprocal modes ofinformation-sharing and their technical, organizational and political barriers and drivers. The aim would be to provide systematically what works for whom in specified stages and circumstances along the pathway of transition for military personnel and their families. The authors are involved in developing such a framework to be used in the establishment and management of a local information-sharing hub for transition service providers and their users.

Second, we suspect that transitions from military to civilian life and their informationsharing properties may not be unique, but share practices and challenges with other policy sectors. Specifically, we are drawn to exploring experiences of personal transitions from other institutionalized service provision, such as from local authority childcare homes to autonomous living and from prison to community life, and to the information-sharing requirements of other service provision such as in integrated health and social care programmes including for troubled families (Wilson et al., 2011; Cornford et al., 2013).

We suggest that responding to such research and development opportunities would contribute not only to the effective transitions to civilian life of the military personnel that have been the subject of this project, but also to the understanding and enhanced effectiveness of information-sharing throughout personal public services.

\section{Acknowledgements}

The authors are grateful to the Forces in Mind Trust that funded the wider project from which 
this paper is drawn (RF350056) and members of the Association of North East Councils who facilitated and advised on the project.

\section{References}

Note: A superscript number at the end of an entry refers to the authors' typology of policy document as:

1. Documents setting out policy or practice guidelines.

2. Reports reviewing, evaluating and otherwise scrutinizing policy and practice.

3. Prescriptions for reform of policy and practice.

6, P., Raab, C. and Bellamy, C. (2005), Joined-up government and privacy in the United Kingdom, Part I. Public Administration, 83, 1, pp. 111-133.

Ashcroft, Lord (2014), The Veterans'Transition Review (www.veteranstransition.co.uk).,3

Allen, J., Langlois, M., and Whittaker, P. (2005), The health needs of ex-prisoners. International Journal for Prisoner Health, 2, 4, pp. 291-301.

CEIS (2014), Information-Sharing Journey Toolkit, Index of Tools, Case Studies (http:// informationsharing.co.uk). ${ }^{3}$

Cornford, J., Baines, S. and Wilson, R. (2013), Representing the family: how does the state 'think family?' Policy and Politics, 41, 1, pp. 1-18.

Dawes, S. S., Cresswell, A. M. and Pardo Theresa, A. (2009), From 'need to know' to 'need to share': tangled problems, information boundaries, and thebuilding of public sector knowledge networks. Public Administration Review, 69, 3, pp. 392-402.

Department for Children, Schools and Families and Department for Communities and Local Government (DCSF-DCLG) (2008), InformationSharing: Guidance for Practitioners and Managers (http://webarchive.nationalarchives.gov.uk). ${ }^{1}$

Forces in Mind Trust (2013), The Transition Mapping Study (http://fim-trust.org). ${ }^{2,3}$

Gateshead Council (2014), Armed Forces Network Annual Report 2013-14. .

Goffman, I. (1968), Asylums (Penguin Books).

Herman, A. and Yarwood, R. (2014), From services to civilian: the geographies of veterans' postmilitary lives. Geoforum, 53, pp. 41-50.

House of Commons Committee of Public Accounts (2008), Ministry of Defence: Leaving the Services, 37th Report of Session 2007-08, HC 351 (The Stationery Office). ${ }^{2,3}$

Independent Commission to Review the UK's Armed Forces (2011), Future Reserves 2020 (The Stationery Office). ${ }^{2,3}$

Information Commissioner's Office (undated), The Guide to Data Protection (http://ico.org.uk). ${ }^{1}$

Iversen, A. et al. (2005), 'Goodbye and good luck': the mental health needs and treatment experiences of British ex-service personnel. The British Journal of Psychiatry, 186, 6, p. 480-486.

Jenkings, K. N., Winter, T. and Woodward, R.
(2008), Presentations of soldiery identity in print media and soldiers' own photographic accounts. In Boll. J. (Ed), War: Interdisciplinary Investigations (Inter-Disciplinary Press), pp. 95-108.

JHOSCNELA (2011), Regional Review of the Health Needs of the Ex-Service Community (www.durham.gov.uk). ${ }^{1}$

JJHOSCNELA(2013), Implementation of Regional Scrutiny Recommendations-Health (www.durham.gov.uk). ${ }^{1}$

Lewis, C., Holmes, L. and Scott-Samuel, A. (2013), Health Needs Assessment For Ex-Armed Forces Personnel Aged Under 65, and their Families (Liverpool Public Health Observatory). ${ }^{2}$

Macdonald, A. (2014), An Exploration of the Veteran Cohort within Durham Tees Valley Probation Trust (Probation Chiefs Association). ${ }^{2}$

MOD (2011), Armed Forces Covenant. ${ }^{1}$

MOD (2014), Service Leavers' Guide. ${ }^{1}$

Nordass, G. (2009), Commando (O'Brien Press).

Stein, M. (2012) Young People Leaving Care (Jessica Kingsley Publishers).

Talbot Rice, R.H. (2009), The Next Generation of Veterans: Their Critical Needs and Their Emerging Rights (www.da.mod.uk). ${ }^{2,3}$

Thomas, M. et al. (2013), Systematic Review of the Literature Relating to Health, Housing, Education, Employment and the Criminal Justice System of those Leaving the Armed Services (Centre for Veteran Wellbeing, University of Chester). ${ }^{2}$

Thompson, J. D. (2003), Organizations in Action (Transaction Publishers).

Richardson, S. and Ashtana, S. (2006), Inter-agency information-sharing in health and social care services. British Journal of Social Work, 36, 4, pp. 657-669.

Wade, J. and Dixon, J. (2006), Making a home, finding a job: investigating early housing and employment outcomes for young people leaving care. Child and Family Social Work, 11, 3, pp. 199208.

Weissman, E. M. et al. (2005), Implementing peerassisted case management to help homeless veterans with mental illness transition to independent housing. Community Mental Health Journal, 41, 3, pp. 267-276. ${ }^{2}$

Wilson R.etal.(2011), Re-mixing digital economies in the voluntary community sector? Social Policy and Society, 10, 3, pp. 379-391.

Windsor, G. (2014), Blog: striking a balance: data protection vs data driven innovation (www.nesta.org.uk). ${ }^{3}$

Woodward, R., Winter, T. and Jenkings, K. N. (2009), Heroic Anxieties: the figure of the British soldier in contemporary print media. Journal of War and Culture Studies, 2, 2, pp. 211-223.

Yang, T.-M. and Maxwell, T.A. (2011), Informationsharing in public organizations. Government 
Information Quarterly, 28, 2, pp. 164-175. 